\title{
Metastases of spinal myxopapillary ependymoma: unique characteristics and clinical management
}

\author{
Theresa Kraetzig, MD,1,2 Lily McLaughlin, BS, ${ }^{1}$ Mark H. Bilsky, MD, ${ }^{1}$ and llya Laufer, MD1 \\ ${ }^{1}$ Department of Neurosurgery, Memorial Sloan Kettering Cancer Center, New York, New York; and 'Department of Neurosurgery, \\ University Medical Center Hamburg-Eppendorf, Hamburg, Germany
}

\begin{abstract}
OBJECTIVE Myxopapillary ependymoma is a benign WHO Grade I tumor most commonly located in the conus-cauda equina region of the spine. Although this tumor is defined by an overall excellent survival, dissemination throughout the whole neuraxis occurs frequently. The current study evaluated the clinical characteristics and significance of myxopapillary ependymoma metastases.
\end{abstract}

METHODS Patients who underwent surgery from 2005 to 2015 for treatment of spinal myxopapillary ependymoma were included in the study. Charts were reviewed for primary tumor symptoms and initial treatment, local recurrence, response to salvage therapy, and presence and behavior of distant metastases.

RESULTS Nineteen patients with spinal myxopapillary ependymoma were included in the study (52.6\% female). The median age at first diagnosis was 32 years old (range $9-58$ years old), and $26.3 \%$ were $\leq 18$ years old. The median follow-up of all included patients was 48 months (range 6-456 months). Of the primary tumors, $84.2 \%$ were located in the lower thoracic or upper lumbar spine, spanning 1-3 levels in $94.7 \%$. All patients underwent surgery for initial treatment: in $78.9 \%$ a gross-total resection (GTR) was achieved, with adjuvant radiation therapy (RT) in $20 \%$. Of the $21.2 \%$ who underwent a subtotal resection (STR), $75 \%$ underwent postoperative RT. Tumor progression was noted in $26.3 \%$ of patients after a median 36-month follow-up (range 12-240 months). In 57.9\% of patients, distant metastases were found, of which $36.4 \%$ were present at initial diagnosis. Further metastases occurred within a median of 20 months (range 2-360 months). Following a diagnosis of metastatic tumor, $72.7 \%$ did not show progression and no symptoms were observed during a median follow-up of 36 months (range 6-216 months). Metastases occurred in all parts of the neuroaxis, but were principally localized in the thoracic and sacral spine in $38.9 \%$ and $33.3 \%$, respectively; the brain was involved in $11.1 \%$. In $54.5 \%$, more than 1 level was affected. Overall survival was $100 \%$ with an excellent clinical and neurological outcome in $78.9 \%$ of cases.

CONCLUSIONS Metastatic dissemination within the CNS can be observed in many patients with myxopapillary ependymoma. GTR of the primary tumor should be the primary treatment goal, and additional RT is recommended after STR. For distant metastases of myxopapillary ependymoma without clinical manifestation, close clinical and MRI follow-up represents a sufficient strategy because most of the metastases remain asymptomatic and do not show progression over time. Additional resection or irradiation as salvage therapy would be recommended if metastases become symptomatic.

https://thejns.org/doi/abs/10.3171/2017.5.SPINE161164

KEY WORDS myxopapillary ependymoma; spinal tumor; metastasis; disease progression; outcome; oncology

$\mathrm{E}$ PENDYMOMAS are tumors of glial origin arising from the ependymal cells, which line the ventricles of the brain and the spinal canal secreting CSF. They are the most common primary tumors of the spinal cord, as up to $60 \%$ of spinal neuroepithelial tumors in adults are ependymomas. ${ }^{7,25}$ The majority of ependymomas are classified as WHO Grade I or II low-grade tumors. Histologically they can further be subdivided into cellular tumors, sub- ependymomas, or myxopapillary ependymomas. The latter, first designated as a distinct clinicopathological entity in 1932 by Kernohan, account for approximately $27 \%$ of spinal ependymomas. ${ }^{16,18,19,28}$ While cellular ependymomas are found throughout the spinal canal and in both intraand extramedullary locations, myxopapillary ependymomas are primarily intradural extramedullary tumors. The majority appear in the lumbar thecal sac in proximity to

ABBREVIATIONS GTR = gross-total resection; RT = radiation therapy; STR = subtotal resection .

SUBMITTED October 3, 2016. ACCEPTED May 23, 2017.

INCLUDE WHEN CITING Published online December 8, 2017; DOI: 10.3171/2017.5.SPINE161164. 
the conus medullaris, cauda equina, or filum terminale. ${ }^{19}$ They are found most commonly in the 4th decade of life, and only $8 \%-20 \%$ occur in children. ${ }^{12,28}$

Myxopapillary ependymomas are characterized by slow growth, resulting in a long natural history with no significant tendency for histological dedifferentiation., ${ }^{7,28}$ However, although classified as a low-grade tumor, myxopapillary ependymomas have a potential for dissemination within the spinal canal. ${ }^{17,28}$ Intracranial spread is rare, but with the common use of MRI, an increasing number of cases of dissemination are found. ${ }^{8,10,20}$ The 5-year overall survival rate of patients with myxopapillary ependymoma is excellent and varies from $90 \%$ to $100 \%$. The available literature has evaluated therapeutic strategies, the improvement of progression-free survival with or without additional radiation therapy (RT) after favorable grosstotal resection (GTR), and the overall outcome. Seeding or distant treatment failure is often described, but to our knowledge no study has analyzed the characteristics of these metastases more closely. Therefore, for the first time, we analyzed the characteristics of distant metastases of spinal myxopapillary ependymoma according to their clinical and biological behavior in one of the largest case series.

\section{Methods \\ Study Population}

From 2005 to 2015, 41 patients underwent surgery at our institution for treatment of spinal ependymoma, and 19 of these patients, who constitute the current study population, had histopathological diagnosis of myxopapillary ependymoma. Four patients underwent primary surgery at other institutions. Records and images were reviewed regarding age at first diagnosis, symptoms at first presentation, and site of primary tumor, as well as initial treatment with extent of surgery and adjuvant therapy. We analyzed recurrence rates, time to recurrence, salvage therapy, and final outcome, with special emphasis on the presence and behavior of distant metastases according to their growth patterns and related symptoms.

\section{Data Collection}

Information about the extent of resection, either subtotal resection (STR) or GTR, was collected from medical records when the first surgery was performed at an outside institution or from our own operative reports and postoperative imaging. The general surgical approach included midline dural opening, with exposure of the tumor in its entirety. In cases of small tumors, without encasement of traversing nerve roots or invasion of the conus medullaris, the tumor capsule was dissected and the tumor was removed en bloc. However, the overwhelming majority of patients in this series had large tumors, and in these cases the tumor capsule was stimulated, coagulated, and incised to perform an intralesional excision. Once adequate decompression of the tumor volume was achieved, the capsule was mobilized and removed while visualizing the surrounding neural elements. The goal of surgery was GTR. GTR was defined as absence of residual tumor mass based on intraoperative microscopic inspection and post- operative MRI. Any case with intraoperatively visible residual tumor was considered STR. Intraoperative electrophysiological monitoring was used in all of the surgeries performed at our institution. Any new enhancing lesions or nodules along the spinal canal or in the brain, which were not related to any other tumor entity or disease, were interpreted as seeding.

\section{Results \\ Patient Characteristics}

An individual patient overview is shown in Table 1 and patient characteristics are summarized in Table 2 . The majority of the cohort was female (52.6\%). The median $( \pm \mathrm{SD})$ age at first diagnosis was $32 \pm 15.1$ years old (range 9-58 years old), 26.3\% $(\mathrm{n}=5)$ were $\leq 18$ years old at first diagnosis, and the median follow-up was $48 \pm 139.0$ months (range 6-456 months).

In 15 (78.9\%) of 19 cases, patients first presented with low-back pain. In 5 patients back pain was the only symptom, whereas in 4 cases without back pain, patients suffered from radiculopathy, sensory deficits, and/or urinary incontinence as the only symptoms. Ten patients presented with additional symptoms to their low-back pain, which were radiculopathy, neurological sensory deficits, motor deficits, and bladder/bowel incontinence in 10, 6, 2, and 3 cases, respectively. The duration of symptoms until first diagnosis ranged from 2 to 36 months (median 6 months).

\section{Tumor Location and Initial Therapy}

The majority of the tumors were located at the level of the conus medullaris or cauda equina (T-11 to L-4, $84.2 \%$, $\mathrm{n}=16)$, spanning $1-3$ levels $(94.7 \%, \mathrm{n}=18$; Table 3, Fig. 1$)$. Nine tumors clearly arose from the filum terminale and 6 tumors had evidence of invasion of the conus medullaris. In 6 cases no exact structure of origin could be detected. Three tumors were primarily located in the lumbosacral spine (L5-S4) and 1 showed extensive disease with tumor filling almost the whole spinal canal from L-2 to L-5 (case 18). All patients underwent surgery as initial treatment. In 15 patients (78.9\%) GTR was reported, and in 4 cases STR was achieved (21.1\%). Three of the latter and 3 others with a GTR who underwent surgery in 1975, 1978, and 1984 received adjuvant $\mathrm{RT}$ for the lumbosacral region. In cases of STR, tumor removal stopped in favor of minimizing chances of neurological deterioration when there was difficulty differentiating tumor from the conus medullaris or inability to dissect the tumor from functional nerve roots.

\section{Local Recurrence}

Five patients $(26.3 \%)$ showed local tumor recurrence after 12-240 months (median 36 months; Table 3), 3 of whom also had recurrent back pain and radiculopathy. Of the 5 local recurrences, 2 underwent STR as first treatment (2/4, 50\% local failure rate), 1 with and 1 without adjuvant RT, whereas in the other 3 GTR was achieved with adjuvant RT in 2 cases $(3 / 15,20 \%$ local failure rate). Salvage therapy for local tumor recurrence was only RT in 2 patients, surgery with RT in 1, and surgery with RT and chemotherapy in another. One asymptomatic patient with local recurrence did not undergo any further local therapy. 
TABLE 1. Individual patient overview

\begin{tabular}{|c|c|c|c|c|c|c|c|c|c|c|c|c|c|}
\hline \multirow[b]{2}{*}{$\begin{array}{c}\text { Case } \\
\text { No. }\end{array}$} & \multirow[b]{2}{*}{$\begin{array}{c}\text { Age at 1st } \\
\text { Dx (yrs), } \\
\text { Sex }\end{array}$} & \multirow[b]{2}{*}{ Tumor Levels } & \multirow[b]{2}{*}{ Resection } & \multirow[b]{2}{*}{$\begin{array}{l}1 s t \\
0 p\end{array}$} & \multirow[b]{2}{*}{$\begin{array}{c}\text { Initial } \\
\text { RT }\end{array}$} & \multicolumn{2}{|c|}{ Local Recurrence } & \multicolumn{3}{|c|}{ Distant Seeding } & \multirow[b]{2}{*}{ Progression } & \multirow[b]{2}{*}{ Sxs } & \multirow[b]{2}{*}{$\begin{array}{c}\text { Total } \\
\text { FU } \\
\text { (mos) }\end{array}$} \\
\hline & & & & & & Present & $\begin{array}{l}\text { Time Until } \\
\text { Recurrence } \\
\text { (mos) }\end{array}$ & Present & $\begin{array}{l}\text { Time Until } \\
\text { Seeding } \\
\text { (mos) }\end{array}$ & Site & & & \\
\hline 1 & $21, \mathrm{M}$ & L3-4 & STR & Out & No & Yes & 12 & Yes & 4 & C, T, B & Yes & Yes & 144 \\
\hline 2 & $42, F$ & L5-S1 & GTR & $\ln$ & No & Yes & 36 & No & - & - & - & - & 108 \\
\hline 3 & $27, \mathrm{M}$ & L3-4 & GTR & $\ln$ & No & No & - & Yes & 2 & $S$ & No & No & 72 \\
\hline 4 & $14, \mathrm{~F}$ & L1-2 & GTR & Out & Yes & Yes & 24 & Yes & 300 & $\mathrm{~T}$ & No & No & 348 \\
\hline 5 & $9, M$ & L2-3 & GTR & Out & Yes & Yes & 240 & Yes & 240 & C, T, B & Yes & Yes & 456 \\
\hline 6 & $30, M$ & S2-4 & STR & $\ln$ & Yes & No & - & Yes & 20 & C & No & No & 48 \\
\hline 7 & $43, M$ & L-3 & GTR & In & No & No & - & Yes & 0 & $\mathrm{~T}, \mathrm{~S}$ & No & No & 36 \\
\hline 8 & $18, F$ & L-3 & GTR & In & No & No & - & No & - & - & - & - & 12 \\
\hline 9 & $41, \mathrm{~F}$ & L-3 & GTR & In & No & No & - & No & - & - & - & - & 18 \\
\hline 10 & $20, F$ & T11-L1 & GTR & In & No & No & - & Yes & 0 & $S$ & No & No & 24 \\
\hline 11 & $18, F$ & L1-2 & GTR & In & No & No & - & Yes & 0 & $\mathrm{~T}, \mathrm{~S}$ & No & No & 6 \\
\hline 12 & $32, \mathrm{M}$ & T12-L2 & GTR & In & No & No & - & Yes & 3 & $\mathrm{~T}$ & No & No & 12 \\
\hline 13 & $50, M$ & L5-S2 & GTR & In & No & No & - & No & - & - & - & - & 6 \\
\hline 14 & $58, F$ & L2-3 & GTR & In & No & No & - & No & - & - & - & - & 24 \\
\hline 15 & $46, F$ & L1-2 & GTR & In & No & No & - & No & - & - & - & - & 6 \\
\hline 16 & $15, \mathrm{M}$ & L2-3 & GTR & Out & Yes & No & - & Yes & 360 & $\mathrm{~T}, \mathrm{~S}$ & Yes & Yes & 396 \\
\hline 17 & $52, \mathrm{~F}$ & T12-L2 & GTR & In & No & No & - & No & - & - & - & - & 66 \\
\hline 18 & $44, \mathrm{~F}$ & L2-5 & STR & In & Yes & No & - & No & - & - & - & - & 84 \\
\hline 19 & $48, M$ & L3-4 \& L4-S1 & STR & $\ln$ & Yes & Yes & 42 & Yes & 0 & $S$ & No & No & 78 \\
\hline
\end{tabular}

$\mathrm{B}=$ brain $; \mathrm{C}=$ cervical; $\mathrm{Dx}=$ diagnosis; FU = follow-up; In = at our institution; Out = at other institution; $\mathrm{S}=$ sacral; Sxs = symptoms; $\mathrm{T}=$ thoracic

\section{Seeding}

In $57.9 \%$ of patients (11/19), distant metastases were observed during follow-up. Characteristics of these patients are summarized in Table 4 and Fig. 2. Metastatic seeding was noted in $36.4 \%(\mathrm{n}=4)$ in the first preoperative wholespine MRI. The others $(63.6 \%, \mathrm{n}=7)$ were detected 2-360 months (median 20 months) after initial diagnosis, although it has to be noted that no imaging data were available for 3 patients diagnosed in the 1970s and 1980s, and 3 others did not undergo a whole-spine scan prior to first surgery. In total, 17 patients were screened for the whole spine and 16 for the brain at any stage of follow-up; 13 of those received scans prior to the first surgery (13/19).

Interestingly, the patient in case 19 appeared to have 2 tumors, which had grown into a single mass ranging from L-3 to S-1. The second tumor located in the sacrum was considered a metastasis, and after STR of both tumors the patient received adjuvant RT. He showed progression of what was considered the primary tumor at L3-4, but not at the other levels where the metastasis was resected subtotally.

Most patients with diagnosed metastatic seeding showed 1 or multiple asymptomatic lesions. Two patients (cases 1 and 5), who did not have evidence of seeding at the time of surgery, developed extensive disease recurrence with metastases in the brain and the cervical and thoracic spine. Growth of these lesions resulted in symptoms of intermittent or chronic pain and unilateral cranial nerve VII and VIII deficits.

Another patient (case 16) demonstrated growing sacral drop metastasis with new paraparesis and bowel and bladder incontinence. All 3 patients underwent 1 (case 16), 2 (case 1), or 4 (case 5) surgeries for L5-S2, the thoracic spine, and/or the brain, respectively. The last 2 were also treated with chemotherapy alone or chemotherapy and RT between surgical procedures. Radiotherapy addressed T12-S2 in case 5, and T7-12, the cervical spine, and the skull base in case 1 . The patient in case 5 , who also underwent 13 courses of temozolomide, showed stable disease, especially of known metastases, during chemotherapy and for another 8 years but then experienced a recurrence or showed growth of residual tumor in the same thoracic location where 1 metastasis had already been resected prior to chemotherapy.

The patients in cases 5 and 16 were diagnosed in 1978 and 1975, respectively, and therefore did not undergo MRI prior to the first surgery and in initial follow-up, until the introduction of MRI. The patient in case 4 did not develop metastases at any stage of follow-up. We included these patients in our cohort because their follow-up durations, with very different courses of the disease, are among the longest reported in the literature.

However, all other cases $(72.7 \%, \mathrm{n}=8)$, including case 4 , displayed no growth or changing impressions on MRI of these lesions over the course of a median follow-up of $32 \pm 26.4$ months (range 6-78 months). In addition, these 8 patients showed no symptoms of the seeding lesions.

\section{Chemotherapy}

None of the patients received chemotherapy as first-line 
TABLE 2. Patient characteristics and clinical onset

\begin{tabular}{|c|c|}
\hline Characteristic & Value \\
\hline No. of patients & 19 \\
\hline Males (\%) & $9(47.4)$ \\
\hline Females (\%) & $10(52.6)$ \\
\hline \multicolumn{2}{|l|}{ Age at Dx (yrs) } \\
\hline Median & 32 \\
\hline SD & 15.1 \\
\hline Min & 9 \\
\hline Max & 58 \\
\hline \multicolumn{2}{|c|}{ Duration of Sxs until 1st Dx (mos) } \\
\hline Median & 6 \\
\hline SD & 10.7 \\
\hline Min & 2 \\
\hline $\operatorname{Max}$ & 36 \\
\hline \multicolumn{2}{|l|}{ No. w/ low-back pain (\%) } \\
\hline Yes & $15(78.9)$ \\
\hline No & $4(21.1)$ \\
\hline \multicolumn{2}{|l|}{ Additional Sxs (\%) } \\
\hline Radiculopathy & $10(52.6)$ \\
\hline Sensory deficits & $6(31.6)$ \\
\hline Motor deficits & $2(10.5)$ \\
\hline Incontinence & $3(15.8)$ \\
\hline No other & $5(26.3)$ \\
\hline \multicolumn{2}{|l|}{ FU time (mos) } \\
\hline Median & 48 \\
\hline SD & 139.0 \\
\hline Min & 6 \\
\hline Max & 456 \\
\hline \multicolumn{2}{|l|}{ Final outcome deficits (\%) } \\
\hline None & $7(36.8)$ \\
\hline Mild & $8(42.1)$ \\
\hline Intermediate & $2(10.5)$ \\
\hline Severe & $2(10.5)$ \\
\hline
\end{tabular}

treatment, but 3 patients (cases 1, 4, and 5) were treated for extensive recurrent local or distant tumor with different regimens, in 2 cases changing regimens, such as carboplatin monotherapy, bevacizumab + carboplatin, bevacizumab monotherapy, bevacizumab + etoposide, etoposide + tamoxifen, temozolomide monotherapy, temozolomide + lapatinib, carmustine, and irinotecan.

\section{Clinical Outcome and Survival}

In all but 2 patients $(89.5 \%, 17 / 19)$, the final outcome at the last documented follow-up evaluation was good. The majority of patients $(78.9 \%, 15 / 19)$ had no deficits $(n=7)$ or just mild pain or mild intermittent sensory or motor deficits, which had no impact on daily life $(n=8)$. Two patients had intermediate deficits, which were defined as right lower-extremity weakness, but the ability to walk without any help, in 1 patient, and left-sided hypacusis and sensory deficits in pinprick and temperature from T-5 to
TABLE 3. Characteristics of the primary tumor

\begin{tabular}{|c|c|}
\hline Characteristic & Value (\%) \\
\hline \multicolumn{2}{|l|}{ Primary level } \\
\hline Cervical & $0(0)$ \\
\hline Thoracic & $3(12)$ \\
\hline Lumbar & $18(72)$ \\
\hline Sacral & $4(16)$ \\
\hline \multicolumn{2}{|l|}{ Levels affected } \\
\hline 1 & $3(15.8)$ \\
\hline 2 & $10(52.6)$ \\
\hline 3 & $5(26.3)$ \\
\hline 4 & $1(5.3)$ \\
\hline \multicolumn{2}{|l|}{ Primary resection } \\
\hline STR & $4(21.1)$ \\
\hline GTR & $15(78.9)$ \\
\hline \multicolumn{2}{|l|}{ Adjuvant RT } \\
\hline No. of patients & 6 \\
\hline For STR & $3(50)$ \\
\hline For GTR & $3(50)$ \\
\hline Adjuvant CT & $0(0)$ \\
\hline Local recurrence & 5 \\
\hline After STR & $2 / 4(50)$ \\
\hline After GTR & $3 / 15(20)$ \\
\hline \multicolumn{2}{|c|}{ Time of recurrence (mos) } \\
\hline Median & 36 \\
\hline SD & 95.3 \\
\hline Min & 12 \\
\hline Max & 240 \\
\hline \multicolumn{2}{|l|}{ Local salvage therapy } \\
\hline Total & 4 \\
\hline RT only & $2(50)$ \\
\hline RT + surgery & $1(25)$ \\
\hline $\mathrm{RT}+$ surgery + CT & $1(25)$ \\
\hline
\end{tabular}

T-8 in the other. Another 2 patients had severe residual problems, such as urinary incontinence, which were present at the time of initial diagnosis and did not resolve after resection of the tumor and decompression of the conus. The other patient-with severe symptoms, chronic neuropathic pain, sensory deficits in all extremities, and weakness in both lower extremities-underwent local irradiation twice and extensive and changing chemotherapeutic regimes for recurrent local disease.

All patients were alive and ambulatory at the last documented follow-up visit.

\section{Discussion}

Despite being histopathologically benign tumors, myxopapillary ependymomas are known to have a tendency to disseminate and recur locally even after a long quiescent period. ${ }^{8,10,28}$ To date, the biological behavior and clinical presentation of myxopapillary ependymoma seeding have not been investigated. In the present study, therefore, we 


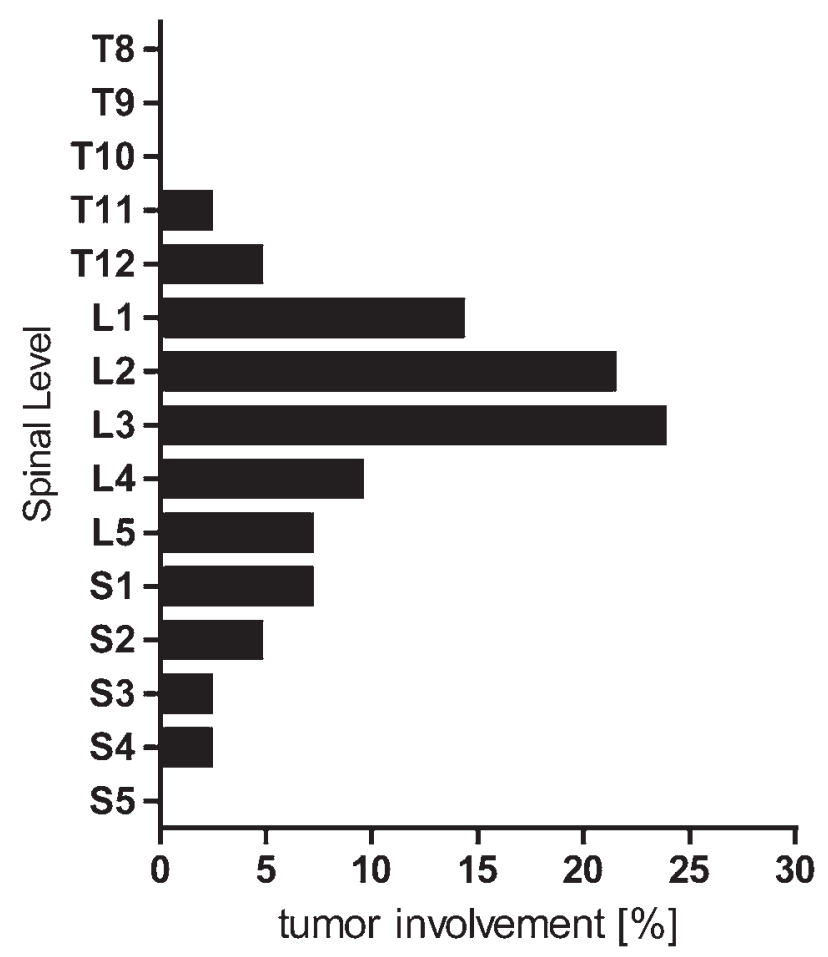

FIG. 1. Graph showing the location of the primary tumor. This figure illustrates the involvement of different levels of the spine (percentages). The majority of myxopapillary ependymomas involved 1-3 levels.

assessed the metastatic occurrence and long-term presentation in patients with myxopapillary ependymoma.

Our cohort is representative of the reported epidemiology as this rare tumor entity in the majority of patients is observed in the 4th decade of life. Only a fraction (10\%-20\%) present in children.,12,28 We cannot confirm the reported bias toward an increased prevalence in males, as we observed a slightly higher bias toward females who were affected more commonly. ${ }^{2,3,29}$ Nonspecific back pain is the most reported symptom at presentation. ${ }^{3,12,28}$ Due to the nonspecific presenting symptoms, diagnosis is delayed in many cases. Consistent with the study of Akyurek et al., the average duration of symptoms in our cohort was 12 months. ${ }^{2}$ However, other studies describe durations ranging from months to years. ${ }^{3,28}$ The delay in diagnosis presumably is, in part, a result of the tumor location, as the primary tumor was located most often $(84.2 \%)$ in the conus-cauda equina region of the lower thoracic and upper lumbar spine, thereby only rarely leading to specific deficits. Furthermore, as the slow growth of the tumor enables the spinal cord and the nerve roots to adapt to compression, only a few patients with myxopapillary ependymomas present with severe deficits, such as incontinence or other neurological impairment, which would require more urgent clinical consultation. ${ }^{3,4}$ Young patients with a prolonged history of nonspecific back pain, and without major risk factors for degenerative disease or other potentially causative trauma, should therefore be considered for MR-based imaging.

Using MRI as the diagnostic tool of choice, imaging of the whole spine and brain should be initiated before
TABLE 4. Characteristics of metastatic dissemination

\begin{tabular}{|c|c|}
\hline Characteristic & Value (\%) \\
\hline Metastases & $11(57.9)$ \\
\hline \multicolumn{2}{|l|}{ Location } \\
\hline Cerebral & $2(11.1)$ \\
\hline Cervical & $3(16.7)$ \\
\hline Thoracic & $7(38.9)$ \\
\hline Lumbar & $0(0.0)$ \\
\hline Sacral & $6(33.3)$ \\
\hline Metastases at presentation & $4(36.4)$ \\
\hline Delayed metastases & $7(63.6)$ \\
\hline \multicolumn{2}{|c|}{ Time to delayed metastases (mos) } \\
\hline Median & 20 \\
\hline SD & 160.4 \\
\hline Min & 2 \\
\hline Max & 360 \\
\hline Progression & $3 / 11(27.3)$ \\
\hline Related Sxs & $3 / 11(27.3)$ \\
\hline Treatment of metastases & $4(36.4)$ \\
\hline Surgery alone & $2(50)$ \\
\hline Surgery + CT & $1(25)$ \\
\hline Surgery + CT + RT & $1(25)$ \\
\hline \multicolumn{2}{|l|}{ FU metastases (mos) } \\
\hline Median & 36 \\
\hline SD & 63.4 \\
\hline Min & 6 \\
\hline Max & 216 \\
\hline \multicolumn{2}{|l|}{ w/ progression } \\
\hline Median & 140 \\
\hline SD & 90.4 \\
\hline Min & 36 \\
\hline Max & 216 \\
\hline \multicolumn{2}{|l|}{ w/o progression } \\
\hline Median & 32 \\
\hline SD & 26.4 \\
\hline Min & 6 \\
\hline Max & 78 \\
\hline
\end{tabular}

the first surgery, because synchronous metastatic seeding to distant sites can already be observed prior to the first surgery. ${ }^{4}$ We generally perform the first postsurgical MRI 2-6 weeks after tumor resection, and then at 6 and 12 months, followed by annual scans. Follow-up screenings should also depict the entire CNS, as metastatic seeding can be observed along the whole craniospinal axis. Furthermore, a lifetime follow-up is highly recommended because of known late recurrence..$^{10,27-29}$

All patients underwent surgery with attempted GTR, which is still considered the therapeutic strategy of choice and the major prognostic factor. However, GTR cannot be achieved in all cases, as our study shows (GTR was accomplished in 78.9\%). The literature shows that in many cases STR had to be accepted because of spinal cord involve- 


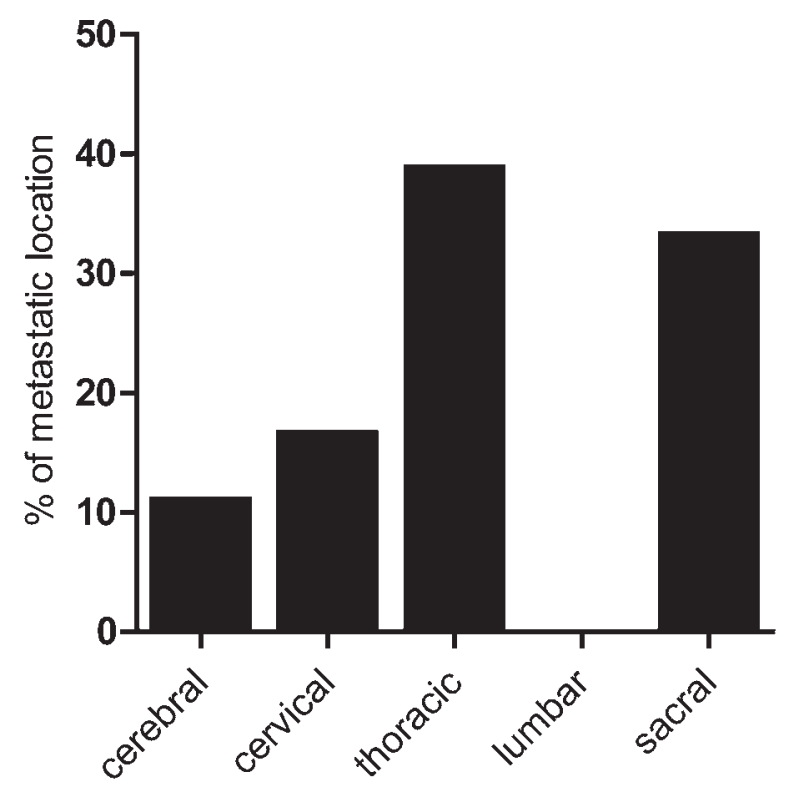

FIG. 2. Graph showing the location of metastatic seeding. Distant metastases localized to either the brain (11.1\%) or the spinal cord (88.9\%). Within the spinal cord, metastases were detected most prominently in the thoracic or sacral region.

ment or lack of clear tumor margins.. ${ }^{2-4,13}$ We agree with these authors in the literature that resection without any violation of the tumor capsule might be difficult in many cases, as in most myxopapillary ependymomas the cauda equina nerves are encased in or strongly attached to the tumor and sometimes this results in STR. STR, however, results in local recurrence rates up to 50\%.,28 Abdulaziz et al. showed a significant correlation between piecemeal resection with capsular violation and tumor recurrence, ${ }^{1}$ but overall survival was not affected by surgical technique. GTR versus STR did not result in significantly different survival rates in a study by Sonneland et al. ${ }^{28}$ In our study, all patients underwent intralesional resection at either the first or second surgery. We found that GTR decreases local recurrence rates by approximately 2.5 -fold compared with tumors that are incompletely resected. There was no correlation between the extent of resection and development of distant metastases.

As adjuvant local RT is the standard treatment for most intracranial ependymomas, its role in spinal myxopapillary ependymoma has changed over time and remains controversial. ${ }^{7}$ Currently, radiation is predominantly used after STR, or as salvage therapy in the case of recurrence. Akyurek et al., however, found a significantly reduced rate of tumor progression in patients who underwent GTR and RT. Yet, one-third of patients show local or distant treatment failure and disease progression., ${ }^{2,13,20,26,29}$ In our study, adjuvant RT was performed in 3 patients who underwent STR. Two of these patients did not show local failure, and another relapsed at 42 months after initial surgery, whereas the 1 patient without adjuvant RT showed recurrent disease only 12 months after STR. Three other patients received adjuvant RT for the lumbosacral region after documented GTR in 1975, 1978, and 1984, 2 of whom developed local recurrence, and all showed seeding at some stage of follow-up. The low number of patients undergoing RT to the primary tumor in the current study limits our ability to draw any conclusions about the utility of RT in this patient population. However, previously published studies support the use of RT as a treatment option for cases in which GTR could not be achieved to reduce local tumor recurrence. ${ }^{10,13,27} \mathrm{We}$, and most other investigators, would not recommend postoperative radiation after GTR up front, as this does not appear to prevent local or distant treatment failure and should be reserved for salvage therapy of local or distant recurrences. ${ }^{4,6,10,12,27}$

Chemotherapy continues to play a limited role in the treatment of ependymoma, and no clear guidelines have been presented for myxopapillary ependymoma. A pooled analysis of Phase II studies has suggested that platinum agents have the highest activity, up to $48 \%$, against ependymomas and chemotherapy combinations result in higher response rates than use of single agents. ${ }^{59}$ None of our patients received chemotherapy as first-line treatment, but 3 did for symptomatic local tumor recurrence and distant metastases. Two received carboplatin as the literature recommends, but had to stop treatment because of bone marrow suppression. Even with different regimens of monotherapy or combination chemotherapy, no response of the tumor or metastases, respectively, could be observed. Only a single patient showed stable recurrent disease over 8 years after multiple cycles of temozolomide, suggesting that this agent might be a promising alternative with a lower risk of side effects than carboplatin (which had also been found for temozolomide in the literature with intracranial anaplastic ependymoma). ${ }^{11,24}$

As noted above, although myxopapillary ependymomas are classified as benign tumors, dissemination and local recurrence pose a major challenge in their clinical treatment. In the literature, dissemination and distant treatment failure are consistently described as occurring approximately $30 \%$ of the time. ${ }^{13,23,29}$ In our cohort, $57.9 \%$ of cases showed seeding either on first presentation or later during follow-up. A comparable percentage of $50 \%$ was recently published by Bandopadhayay and colleagues, who analyzed 18 children under the age of 21 years with myxopapillary ependymoma. ${ }^{4}$ As described above, MRI remains the gold standard in diagnosing myxopapillary ependymoma recurrences. With further improvements in the resolution of MRI, even very small leptomeningeal seeding can be detected. A few authors suggest a workup of the CSF, but the number of patients with positive samples is very low ${ }^{22,29}$ and positive samples were only observed in cases with widespread seeding and involvement of other organs..$^{15}$ While there may be a role for CSF sampling in the setting of conflicting clinical and MRI data, lumbar spinal taps do not have a prominent role in the diagnostic workup of these patients. In the near future, circulating tumor DNA might present as an additional option to allow for liquid biopsy if tumor relapse is suspected. Until then, a close MRI-based follow-up is recommended, at least annually. Earlier scans should be performed if the patient presents new symptoms, such as new back pain or radicular pain, as well as neurological deficits, or if the last MRI showed any suspicious contrast enhancement.

The proportion of patients presenting with metastases 
at initial diagnosis ranges between $36.4 \%$ and $50 \%$, as observed in our study and by Bandopadhayay et al. ${ }^{4}$ This weakens the hypothesis that tumor cells are predominantly disseminated into the CSF due to surgical manipulation or violation of the tumor capsule, as stated in some papers. ${ }^{1,21,23}$ To our knowledge, there is no study to date that analyzes the presence of tumor cells in the CSF. Dissemination to the brain is more often reported in recent papers, and occasionally supratentorial lesions are described. 2,20,21,30 Bandopadhayay et al. found a mean time to dissemination of 25 months and also reported 2 cases of intracranial spread. ${ }^{4}$ In our cohort there was extensive seeding with metastases throughout the whole neuraxis, including the brain in cases 1 and 5. Furthermore, the time to widespread dissemination varied in those 2 cases between 4 and 240 months, which shows the varying onset of metastases. The patient in case 5, however, was initially diagnosed in 1978 without MRI for several years, so we cannot exclude an earlier onset of dissemination than the reported 240 months.

We did not observe any systemic dissemination, which is consistent with data from other studies, and furthermore presumably appears to be more common in cases of primary extraspinal location. ${ }^{2,14,20,28}$ In patients in whom seeding was detected at some stage of follow-up, the age ranged from 9 to 48 years old at diagnosis (median 21 years old, mean 25.2 years old). In 1 of our cases (case 16) a thoracic manifestation remained stable, whereas a sacral drop metastasis grew and became symptomatic during the same follow-up period. Thus, the behavior of metastases differed within individual patients.

In the majority of patients with metastatic seeding we did not observe any radiological progression or clinical manifestation. Very few other publications also note that most metastases do not become symptomatic and remain stable over long periods of time without demonstrating signs of growth progression. ${ }^{4,13}$ Consistent with the abovementioned studies, a "watch and wait" strategy may be reasonable in patients with limited seeding until symptoms occur or radiological examinations show disease progression..$^{4,21}$ In the current study, patients without progression of metastases had shorter median follow-up durations than the group with progression, therefore possibly underestimating the true frequency of progression. All 3 patients who showed radiological progression of their seeding also developed symptoms. Therefore, these data support spinal imaging at the time of symptomatic progression.

The outcome of patients with disseminated tumors in our study did not differ from that of patients with solitary lesions, which is in agreement with previously published data. ${ }^{27,28}$ Clear delineation of risk factors and optimal therapeutic strategies for patients with seeding or local progression of myxopapillary ependymoma would require well-designed multicenter and multidisciplinary prospective studies.

\section{Conclusions}

Patients with myxopapillary ependymoma have excellent overall survival, but are at high risk of CNS dissemination at the time of diagnosis or during follow-up. After diagnosis, the primary treatment modality is surgical removal of the primary tumor with the goal of GTR. When only an STR can be achieved, adjuvant RT may be considered to prevent or delay tumor recurrence depending on the age of the patient. For detection and monitoring of distant metastases, close follow-up MRI is recommended. Interestingly, our study shows that many metastases remain clinically stable without radiological signs of progression. These data suggest that close observation of myxopapillary ependymoma seeding may represent a safe strategy, with therapy reserved for rare cases of symptomatic progression.

\section{References}

1. Abdulaziz M, Mallory GW, Bydon M, De la Garza Ramos R, Ellis JA, Laack NN, et al: Outcomes following myxopapillary ependymoma resection: the importance of capsule integrity. Neurosurg Focus 39(2):E8, 2015

2. Akyurek S, Chang EL, Yu TK, Little D, Allen PK, McCutcheon I, et al: Spinal myxopapillary ependymoma outcomes in patients treated with surgery and radiotherapy at M.D. Anderson Cancer Center. J Neurooncol 80:177-183, 2006

3. Bagley CA, Wilson S, Kothbauer KF, Bookland MJ, Epstein F, Jallo GI: Long term outcomes following surgical resection of myxopapillary ependymomas. Neurosurg Rev 32:321334, 2009

4. Bandopadhayay P, Silvera VM, Ciarlini PDSC, Malkin H, Bi WL, Bergthold G, et al: Myxopapillary ependymomas in children: imaging, treatment and outcomes. J Neurooncol 126:165-174, 2016

5. Bouffet E, Foreman N: Chemotherapy for intracranial ependymomas. Childs Nerv Syst 15:563-570, 1999

6. Chan HS, Becker LE, Hoffman HJ, Humphreys RP, Hendrick EB, Fitz CR, et al: Myxopapillary ependymoma of the filum terminale and cauda equina in childhood: report of seven cases and review of the literature. Neurosurgery 14:204210, 1984

7. Chan MD, McMullen KP: Multidisciplinary management of intracranial ependymoma. Curr Probl Cancer 36:6-19, 2012

8. Davis C, Barnard RO: Malignant behavior of myxopapillary ependymoma. Report of three cases. J Neurosurg 62:925929, 1985

9. Duffner PK, Horowitz ME, Krischer JP, Friedman HS, Burger PC, Cohen ME, et al: Postoperative chemotherapy and delayed radiation in children less than three years of age with malignant brain tumors. N Engl J Med 328:1725-1731, 1993

10. Fassett DR, Pingree J, Kestle JRW: The high incidence of tumor dissemination in myxopapillary ependymoma in pediatric patients. Report of five cases and review of the literature. J Neurosurg 102 (1 Suppl):59-64, 2005

11. Freyschlag CF, Tuettenberg J, Lohr F, Thomé C, Schmieder $\mathrm{K}$, Seiz M: Response to temozolomide in supratentorial multifocal recurrence of malignant ependymoma. Anticancer Res 31:1023-1025, 2011

12. Gagliardi FM, Cervoni L, Domenicucci M, Celli P, Salvati M: Ependymomas of the filum terminale in childhood: report of four cases and review of the literature. Childs Nerv Syst 9:3-6, 1993

13. Gilhuis HJ, Kappelle AC, Beute G, Wesseling P, Grotenhuis A, Boerman RH: Radiotherapy for partially resected spinal ependymomas: a retrospective study of 60 cases. Oncol Rep 10:2079-2082, 2003

14. Helwig EB, Stern JB: Subcutaneous sacrococcygeal myxopapillary ependymoma. A clinicopathologic study of 32 cases. Am J Clin Pathol 81:156-161, 1984

15. Ilhan-Mutlu A, Berghoff AS, Furtner J, Dieckmann K, Slave 
I, Czech T, et al: High plasma-GFAP levels in metastatic myxopapillary ependymoma. J Neurooncol 113:359-363, 2013

16. Kernohan J: Primary tumors of the spinal cord and intradural filum terminale, in Penfield W (ed): Cytology and Cellular Pathology of the Nervous System. New York: Hoeber, 1932

17. Kleihues P, Cavenee WK (eds): Ependymomas, in World Health Organization Classification of Tumours: Pathology and Genetics. Tumours of the Nervous System. Oxford: Oxford University Press, 2000

18. Louis DN, Ohgaki H, Wiestler OD, Cavenee WK, Burger PC, Jouvet A, et al: The 2007 WHO classification of tumours of the central nervous system. Acta Neuropathol 114:97-109, 2007

19. Mork SJ, Loken AC: Ependymoma: a follow-up study of 101 cases. Cancer 40:907-915, 1977

20. Pica A, Miller R, Villà S, Kadish SP, Anacak Y, Abusaris H, et al: The results of surgery, with or without radiotherapy, for primary spinal myxopapillary ependymoma: a retrospective study from the rare cancer network. Int J Radiat Oncol Biol Phys 74:1114-1120, 2009

21. Plans G, Brell M, Cabiol J, Villà S, Torres A, Acebes JJ: Intracranial retrograde dissemination in filum terminale myxopapillary ependymomas. Acta Neurochir (Wien) 148:343-346, 2006

22. Qian X, Goumnerova LC, De Girolami U, Cibas ES: Cerebrospinal fluid cytology in patients with ependymoma: a biinstitutional retrospective study. Cancer 114:307-314, 2008

23. Rezai AR, Woo HH, Lee M, Cohen H, Zagzag D, Epstein FJ: Disseminated ependymomas of the central nervous system. J Neurosurg 85:618-624, 1996

24. Rudà R, Bosa C, Magistrello M, Franchino F, Pellerino A, Fiano V, et al: Temozolomide as salvage treatment for recurrent intracranial ependymomas of the adult: a retrospective study. Neuro Oncol 18:261-268, 2016

25. Russell D, Rubinstein L: Tumors of central neuroepithelial origin, in Pathology of Tumors of the Nervous System. Baltimore: Williams \& Wilkins, 1989
26. Schild SE, Nisi K, Scheithauer BW, Wong WW, Lyons MK, Schomberg PJ, et al: The results of radiotherapy for ependymomas: the Mayo Clinic experience. Int J Radiat Oncol Biol Phys 42:953-958, 1998

27. Schweitzer JS, Batzdorf U: Ependymoma of the cauda equina region: diagnosis, treatment, and outcome in 15 patients. Neurosurgery 30:202-207, 1992

28. Sonneland PR, Scheithauer BW, Onofrio BM: Myxopapillary ependymoma. A clinicopathologic and immunocytochemical study of 77 cases. Cancer 56:883-893, 1985

29. Weber DC, Wang Y, Miller R, Villà S, Zaucha R, Pica A, et al: Long-term outcome of patients with spinal myxopapillary ependymoma: treatment results from the MD Anderson Cancer Center and institutions from the Rare Cancer Network. Neuro Oncol 17:588-595, 2015

30. Woesler B, Moskopp D, Kuchelmeister K, Schul C, Wassmann $\mathrm{H}$ : Intracranial metastasis of a spinal myxopapillary ependymoma. A case report. Neurosurg Rev 21:62-65, 1998

\section{Disclosures}

Dr. Laufer reports being a consultant for DePuy/Synthes, SpineWave, Globus, and Medtronic.

\section{Author Contributions}

Conception and design: Laufer, Kraetzig, Bilsky. Acquisition of data: Kraetzig, McLaughlin. Analysis and interpretation of data: Kraetzig. Drafting the article: Kraetzig. Critically revising the article: Laufer, Kraetzig, Bilsky. Reviewed submitted version of manuscript: all authors. Approved the final version of the manuscript on behalf of all authors: Laufer. Administrative/technical/ material support: McLaughlin. Study supervision: Laufer, Bilsky.

\section{Correspondence}

Ilya Laufer, Department of Neurosurgery, Memorial Sloan Kettering Cancer Center, 1275 York Ave., New York, NY 10065. email: lauferi@mskcc.org. 